\title{
Mycobiota in the Carposphere of Sour and Sweet Cherries and Antagonistic Features of Potential Biocontrol Yeasts
}

\author{
Ramunè Stanevičienė ${ }^{1}$, Juliana Lukša ${ }^{1}$, Živilè Strazdaitè-Žielienè ${ }^{1}$, Bazilè Ravoitytė ${ }^{1}$, \\ Regina Losinska-Sičiūniené ${ }^{1}$, Raimondas Mozūraitis ${ }^{2}$ (1) and Elena Servienè ${ }^{1, *}$ \\ 1 Laboratory of Genetics, Institute of Botany, Nature Research Centre, Akademijos str. 2, \\ LT-08412 Vilnius, Lithuania; ramune.staneviciene@gamtc.lt (R.S.); juliana.luksa@gamtc.lt (J.L.); \\ zivile.strazdaite-zieliene@gamtc.lt (Ž.S.-Ž.); bazile.ravoityte@gamtc.lt (B.R.); \\ regina.losinska-siciuniene@gamtc.lt (R.L.-S.) \\ 2 Laboratory of Chemical and Behavioral Ecology, Institute of Ecology, Nature Research Centre, \\ Akademijos str. 2, LT-08412 Vilnius, Lithuania; raimondas.mozuraitis@gamtc.lt \\ * Correspondence: elena.serviene@gamtc.lt; Tel.: +370-5-272-93-63
}

\section{check for} updates

Citation: Stanevičienè, R.; Lukša, J.; Strazdaitè-Žielienè, Ž.; Ravoitytè, B.; Losinska-Sičiūnienè, R.; Mozūraitis,

R.; Servienè, E. Mycobiota in the Carposphere of Sour and Sweet Cherries and Antagonistic Features of Potential Biocontrol Yeasts.

Microorganisms 2021, 9, 1423. https:// doi.org/10.3390/microorganisms 9071423

Academic Editors: Agapi

I. Doulgeraki and Chrysoula Tassou

Received: 3 June 2021

Accepted: 28 June 2021

Published: 30 June 2021

Publisher's Note: MDPI stays neutral with regard to jurisdictional claims in published maps and institutional affiliations.

Copyright: (c) 2021 by the authors. Licensee MDPI, Basel, Switzerland. This article is an open access article distributed under the terms and conditions of the Creative Commons Attribution (CC BY) license (https:/ / creativecommons.org/licenses/by/ $4.0 /)$.

\begin{abstract}
Sour cherries (Prunus cerasus L.) and sweet cherries (P. avium L.) are economically important fruits with high potential in the food industry and medicine. In this study, we analyzed fungal communities associated with the carposphere of sour and sweet cherries that were freshly harvested from private plantations and purchased in a food store. Following DNA isolation, a DNA fragment of the ITS2 rRNA gene region of each sample was individually amplified and subjected to high-throughput NGS sequencing. Analysis of 168,933 high-quality reads showed the presence of 690 fungal taxa. Investigation of microbial ASVs diversity revealed plant-dependent and postharvest handling-affected fungal assemblages. Among the microorganisms inhabiting tested berries, potentially beneficial or pathogenic fungi were documented. Numerous cultivable yeasts were isolated from the surface of tested berries and characterized by their antagonistic activity. Some of the isolates, identified as Aureobasidium pullulans, Metschnikowia fructicola, and M. pulcherrima, displayed pronounced activity against potential fungal pathogens and showed attractiveness for disease control.
\end{abstract}

Keywords: P. cerasus; P. avium; cherry; yeasts; fungal communities; antagonistic activity

\section{Introduction}

Sour cherries (Prunus cerasus L.) and sweet cherries (P. avium L.) belong to the family of the Rosaceae [1] and are economically and agronomically important crops. These species are cultivated in temperate and cool regions and characterized by a scattered distribution from the Black Sea to Ireland and Spain, and from Scandinavia to Africa [2]. Cherry fruits are a nutrient-dense food with relatively low caloric content, important nutrients, and significant amounts of bioactive food components, having positive effects on human health [3].

Sour cherry is cultivated for its sharp and juicy fruits that are mostly destined to produce foods like jam, jelly, and syrup or alcohol beverages such as wine, brandy, and fruit beer $[1,4]$. The current research suggests that intake of fresh sour cherry berries or juice promotes health due to the positive action of anthocyanins and phenolic compounds [3,5]. The consumption of cherries may reduce the risk of arthritis, cancer, cardiovascular disease, and diabetes, and may improve sleep and cognitive functions [3].

Sweet cherry is one of the most economically important fruit species in the world. Most sweet cherry fruits are consumed fresh or processed as frozen, dried, or juiced [3]. Sweet cherry berries are rich in bioactive compounds, including flavonoids, anthocyanins, carotenoids, vitamins, ascorbic acid, and potassium [6,7]. Both laboratory assays and clinical trials have demonstrated the anti-inflammatory, antimicrobial, and anticarcinogenic properties of sweet cherry fruits and their metabolites $[6,8]$. 
The plant carposphere is highly colonized by various bacterial and fungal microorganisms, the distribution of which is affected by geographic location, climatic conditions, plant species, ripening stage, and growing methods [9-11]. Some epiphytic plant-associated microorganisms demonstrate beneficial features, produce secondary metabolites improving resistance in the plant, and impact the structure of the microbial population [12-14]. On the other hand, some fruit-inhabiting microorganisms are recognized as pathogenic to hosting plants and humans and are responsible for significant economic losses and serious health problems $[15,16]$. Therefore, postharvest handling and processing of fruits encounter exceptional attention due to the control of microbiological hazards $[17,18]$.

The scarcity of works characterizing sweet and sour cherries microbial communities are of certain importance. Based on high-throughput sequencing of the 16S rRNA gene, the nitrogen-fixing bacterial community inhabiting Prunus avium L. leaves was described [19] and bacterial diversity of pitted sweet cherries, proceeded high-hydrostatic pressure processing, was evaluated [20]. Endophytic fungi associated with Prunus avium and Prunus cerasus trees located in Germany and Iran were isolated and examined by morphological and molecular analysis [21,22]. Microorganisms present on different cultivars of sour cherries in Hungary were evaluated using cultivation techniques only [18]. It was demonstrated that the frequency of distribution of bacteria, molds, and yeasts were very similar in spite of different cultivars, growing methods, and growing years [18]. To the best of our knowledge, there is no information on sweet and sour cherries carposphere-associated fungal microorganism communities.

The main objectives of this study were: (i) to characterize the fungal communities distributed on freshly harvested P. avium and P. cerasus berries and compare with a food store sour cherry, (ii) to isolate and identify the cultivable yeasts associated with sweet and sour cherries to explore their biocontrol potential, and (iii) to assess the antagonistic activity of isolated fungi against other yeasts, including potential pathogens. We aim to better understand the abundance of fungi on the surface of cherries and evaluate the differences between the fungal communities. This research employs natural resources to explore the properties of environmental fungi and dedicates particular attention to the fight against potential pathogens. Obtained results may aid in developing eco-friendly biocontrol tools.

\section{Materials and Methods}

\subsection{Sampling of Berries}

Sweet cherries (P. avium L.) were harvested three times in June 2020 from 8-10-yearold sweet cherry trees located in a private plantation in the Alytus region of Lithuania (GPS coordinates: $54^{\circ} 23^{\prime} 43.8^{\prime \prime} \mathrm{N}, 23^{\circ} 56^{\prime} 18.7^{\prime \prime}$ E). Sour cherries (P. cerasus L.) were sampled three times on July 2020 from the 8-12-year-old trees located in a private plantation in the Vilnius region of Lithuania (GPS coordinates: $54^{\circ} 45^{\prime} 08.2^{\prime \prime} \mathrm{N}, 25^{\circ} 17^{\prime} 10.0^{\prime \prime} \mathrm{E}$ ). Sterile gloves and plastic bags were used to aseptically collect berries, and samples were processed in the laboratory within $3 \mathrm{~h}$ after harvesting. At each sampling, the berries were collected from different cherry trees and combined into one biological replicate at each location. In total, three sweet cherries samples (PA-PL1, PA-PL2, and PA-PL3) and three samples of sour cherries (PC-PL1, PC-PL-2, and PC-PL3) were collected from private plantations and prepared for further analysis. In addition, sour cherries, which originated from conventional orchards of Hungary, were purchased at the "ready-to-eat" ripening stage in June 2020 from a local food store (Vilnius, Lithuania) (samples PC-FS1, PC-FS2, and PC-FS3) and kept under refrigeration for no more than $3-4 \mathrm{~h}$ before processing.

\subsection{Yeast Isolation and Culturing}

To determine the viable population of yeasts distributed on sweet and sour cherries, about $25 \mathrm{~g}$ of the berries were placed in a $30 \mathrm{~mL}$ of liquid $\mathrm{MD}$ medium ( $2 \%$ dextrose, $1 \%$ $\left(\mathrm{NH}_{4}\right)_{2} \mathrm{SO}_{4}, 0.09 \% \mathrm{KH}_{2} \mathrm{PO}_{4}, 0.05 \% \mathrm{MgSO}_{4}, 0.023 \% \mathrm{~K}_{2} \mathrm{HPO}_{4}, 0.01 \% \mathrm{NaCl}, 0.01 \% \mathrm{CaCl}_{2}$ ) for $1 \mathrm{~h}$ at room temperature with shaking at $100 \mathrm{rpm}$. Outwashes were serially diluted in MD medium, and $0.1 \mathrm{~mL}$ aliquots were plated in triplicate on yeast-extract-peptone- 
dextrose (YPD)-agar plates (1\% yeast extract, $1 \%$ peptone, $2 \%$ dextrose, $2 \%$ agar) containing $50 \mu \mathrm{g} \mathrm{mL}{ }^{-1}$ chloramphenicol for detection and enumeration of cultivable yeasts. To capture yeasts distributed in low quantities on the tested berries, the enrichment technique was used. Collected berries (15 g of each sample) were kept in 5\% dextrose solution for 15 days at a temperature of $22{ }^{\circ} \mathrm{C}$ and afterward were plated on YPD-agar. Plates were incubated at $25{ }^{\circ} \mathrm{C}$ for $3-5$ days and CFUs were counted. Results were expressed as $\log \mathrm{CFU} / \mathrm{g}$ berries. Representatives of morphologically different yeast-like colonies were purified by streaking on YPD-agar medium and subjected to molecular identification and antagonistic activity analysis.

\subsection{Molecular Identification of Yeast Species}

Genomic DNA was isolated from freshly grown yeast cells ( $24 \mathrm{~h})$. Genomic DNA purification kit (Thermo Fisher Scientific Baltics, Vilnius, Lithuania) following the manufacturer's instructions was employed. For the identification of yeast, PCR amplification of the region between the 18S rRNA and 28S rRNA genes containing two non-coding spacers (ITS-A and ITS-B) separated by the $5.8 \mathrm{~S}$ rRNA gene was performed using ITS1 $\left(5^{\prime}-\right.$ TCCGTAGGTGAACCTGCGG-3') and ITS4 (5'-TCCTCCGCTTATTGATATGC-3') primers or the D1/D2 region of 26S rDNA was amplified using NL1 (5'-GCATATCAATAAGCGGA GGAAAAG-3') and NL4 (5'-GGTCCGTGTTTCAAGACGG-3') primers. The PCR amplification was performed as described in [23]; except for D1/D2 region amplification, annealing temperature was $52^{\circ} \mathrm{C}$. Amplified products were purified using a GeneJet PCR purification kit (Thermo Fisher Scientific Baltics, Vilnius, Lithuania) and sequenced using ITS1 and/or NL1 primers at BaseClear (Leiden, Netherlands). The generated sequences were compared with those found in the FASTA network service of the EMBL-EBI database (http: / / www.ebi.ac.uk/Tools / sss / fasta/nucleotide.html (accessed on 12 May 2021) and deposited in the National Center for Biotechnology Information (NCBI) under accession numbers MZ185321-MZ185356, MZ185358-MZ185371.

\subsection{Determination of Sour and Sweet Cherry Fungal Microbiota by Next Generation Sequencing}

For metagenomic analysis, microbial suspension from the surface of cherries was obtained under aseptic conditions by washing $300 \mathrm{~g}$ of representative berries with $500 \mathrm{~mL}$ of sterile $0.05 \mathrm{M}$ phosphate buffer solution ( $\mathrm{pH}$ 6.8) for $1 \mathrm{~h}$ with shaking at $120 \mathrm{rpm}$. The obtained microbial cell suspension was centrifuged in $50 \mathrm{~mL}$ Falcon test tubes at $5000 \times g$ for $20 \mathrm{~min}$, and the resulting pellets were collected in one Eppendorf tube, centrifuged at $12,000 \times g$ for $10 \mathrm{~min}$, and used for DNA extraction. Genomic DNA of fungi was isolated from $40 \mathrm{mg}$ of sediments obtained from respective berries using a Genomic DNA purification kit (Thermo Fisher Scientific Baltics, Vilnius, Lithuania) and following the manufacturer's protocol. The extracted DNA was tested for quantity and purity using Nanodrop 2000 spectrophotometer (Thermo Fisher Scientific). The ITS primer pair, ITS3KYO2 (5'-GATGAAGAACGYAGYRAA-3') and ITS4 (5'-TCCTCCGCTTATTGATATGC$\left.3^{\prime}\right)$, was used to amplify the fungal internal transcribed spacer (ITS) DNA region ITS2. Amplicon libraries were prepared using modified Illumina adapters (www.illumina.com (accessed on 10 February 2021), and quality was checked on an Agilent Technologies Bioanalyzer DNA 1000. Amplicon sequencing was performed on the Illumina MiSeq platform to obtain paired-end reads $(2 \times 300 \mathrm{bp})$ (BaseClear B.V., Leiden, The Netherlands). Complete data sets were submitted to the National Center for Biotechnology Information (NCBI) Sequence Read Archive (SRA) database (Accession number PRJNA729235).

\subsection{Bioinformatics and Data Analysis}

Sequences were processed and analyzed using QIIME 2 v2020.6 open-source software https: / / qiime2.org (accessed on 7 July 2020) [24]. The obtained forward and reverse reads were trimmed with Cutadapt 2.8 to remove primer sequences [25]. Paired-end reads were processed with Divisive Amplicon Denoising Algorithm 2 (DADA2 pipeline http: / / qiime2 .org (accessed on 15 February 2021). Low quality reads with an expected error rate higher 
than 3.7 for reverse and 2.0 for forward reads were discarded. Chimeric sequences and singletons were excluded using the 'consensus' method [26]. Obtained unique amplicon sequence variants (ASVs) were assigned taxonomy by aligning to the latest UNITE v8.2 dynamic reference database (build 15 January 2020) at 97\% similarity using QIIME q2feature-classifier plugin [27]. The other parameters were used as default. Fungal data for alpha and beta diversity analyses were rarefied to the minimum sequence count per berry sample $(17,100)$ using the q2-diversity plugin. Alpha diversity was calculated by Shannon's diversity index, observed ASVs, and Pielou's measure of species evenness. Kruskal-Wallis test was used for taxa comparisons, calculated in QIIME 2. Permutational multivariate analysis of variance (PERMANOVA) with 999 random permutations was used to analyze statistical differences in beta diversity. Principal coordinate analysis (PCoA) plots were constructed using Jaccard distances with ggfortify tools in R v1.3.1056 [28]. Heatmap was visualized using gplot package in R [29].

\subsection{In Vitro Evaluation of Yeast Antagonistic Activity}

For detection of killing phenotype, MBA agar plates ( $0.5 \%$ yeast extract, $0.5 \%$ peptone, $2 \%$ dextrose, $2 \%$ agar, $0.002 \%$ methylene blue, $\mathrm{pH} 4.8$ ) were seeded with a lawn $\left(2 \times 10^{6}\right.$ cells / plate) of the sensitive Saccharomyces cerevisiae strain BY4741 (MATa; his3 D1; leu2D0; met15D0; ura3D0 (KIL-0)) (Thermo Scientific Molecular Biology, Lafayette, CO, USA) or strains of different yeast species (Rhodotorula graminis, R. glutinis, Candida albicans, C. guilermondii, Sporobolomyces roseus, Cryptococcus wieringae, Aureobasidium pullulans). The tested yeast strains were spotted on the top of the plates and followed incubation at $25^{\circ} \mathrm{C}$ for 3 days. The killer activity was evaluated based on the appearance of clear zones of growth inhibition surrounding the spotted cells.

\section{Results}

\subsection{Abundance and Diversity of Fungal Microbiota on P. cerasus and P. avium}

The fungal community of sweet and sour cherry samples was revealed by Next Generation Sequencing (NGS) of the ITS2 region of fungal rDNA amplified from total DNA extracted from the surface of cherry samples. Illumina MiSeq sequencing generated a total of 257,984 raw reads. After data quality filter processing, the number of high quality ITS reads for sweet and sour cherries was 168,933 with an average of 18,770 sequences per sample (range 17,104-21,140) (Table 1). The clustering of the sequences at $97 \%$ sequence identity generated a total of 690 ASVs (Table 1). The highest number of ASVs was observed in sour cherries harvested from private plantation 317 [109 \pm 5.77 , hereafter median for 3 samples \pm standard deviation], next followed sweet cherries 194 [71 \pm 10.97$]$, and the lowest number was in store-purchased sour cherries 179 [58 \pm 14.57 ] (Table 1).

Table 1. Total sequences obtained for fungal community samples of sour (PC-PL) and sweet (PA-PL) cherries freshly harvested from private plantations as well as food store sour cherries (PC-FS).

\begin{tabular}{ccccccc}
\hline & $\begin{array}{c}\text { Reads } \\
\text { Obtained }\end{array}$ & $\begin{array}{c}\text { HQ } \\
\text { Reads }\end{array}$ & $\begin{array}{c}\text { Observed } \\
\text { ASVs }\end{array}$ & $\begin{array}{c}\text { Pielou } \\
\text { Evenness }\end{array}$ & $\begin{array}{c}\text { Shannon } \\
\text { Diversity }\end{array}$ & $\begin{array}{c}\text { Simpson } \\
\text { Index }\end{array}$ \\
\hline PC-PL1 & 26,895 & 17,126 & 99 & 0.63 & 4.2 & 0.86 \\
PC-PL2 & 28,665 & 19,082 & 109 & 0.66 & 4.46 & 0.91 \\
PC-PL3 & 30,732 & 21,140 & 109 & 0.65 & 4.37 & 0.92 \\
PA-PL1 & 27,571 & 20,325 & 71 & 0.45 & 2.75 & 0.72 \\
PA-PL2 & 28,473 & 17,509 & 52 & 0.54 & 3.08 & 0.78 \\
PA-PL3 & 29,021 & 19,901 & 71 & 0.58 & 3.59 & 0.86 \\
PC-FS1 & 27,825 & 17,104 & 46 & 0.65 & 3.58 & 0.85 \\
PC-FS2 & 30,369 & 19,242 & 58 & 0.65 & 3.78 & 0.87 \\
PC-FS3 & 28,433 & 17,504 & 75 & 0.68 & 4.26 & 0.92 \\
\hline Total: & 257,984 & 168,933 & 690 & & & \\
\hline
\end{tabular}


The mycobiota analysis according to the nonparametric Kruskal-Wallis test showed significant differences in fungal diversity amongst sour and sweet cherries collected from private plantations.

Alpha diversity metrics, such as Shannon diversity index $(p=0.049)$ and Pielou's measure of evenness index ( $p$-value 0.0495$)$ were statistically different between PC-PL and PA-PL samples (Figure 1). The observed number of ASVs revealed a significant difference in fungal community richness between PC-PL vs. PA-PL as well as PC-PL vs. PC-FS samples (ASVs index $p$-values were 0.043 and 0.046 , respectively). In agreement with ASV data, Shannon's diversity and the Simpson estimates revealed that sour cherries had higher fungal diversity than sweet cherries or food store cherries (Table 1). No statistical differences in alpha diversity metrics were detected between sweet cherries collected from the private plantation and sour cherries from a store (Figure 1).

A

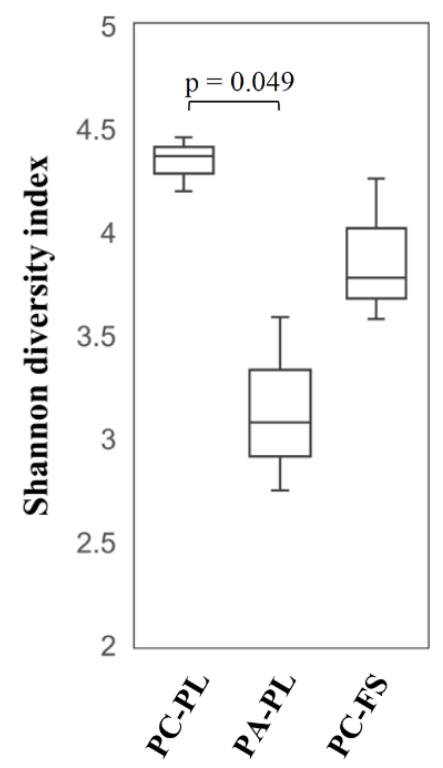

B

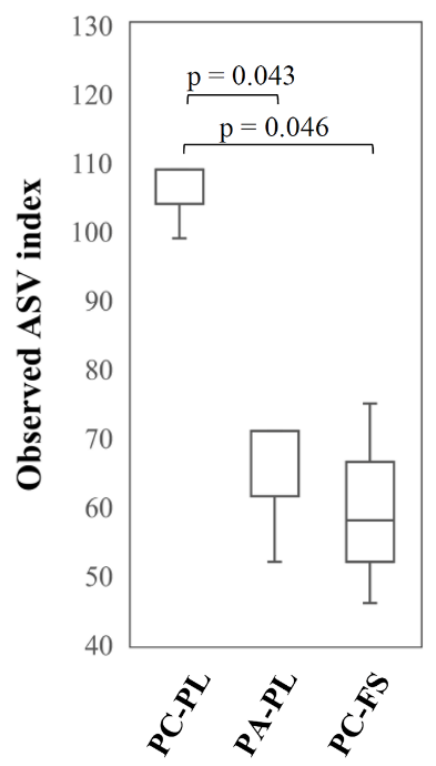

C

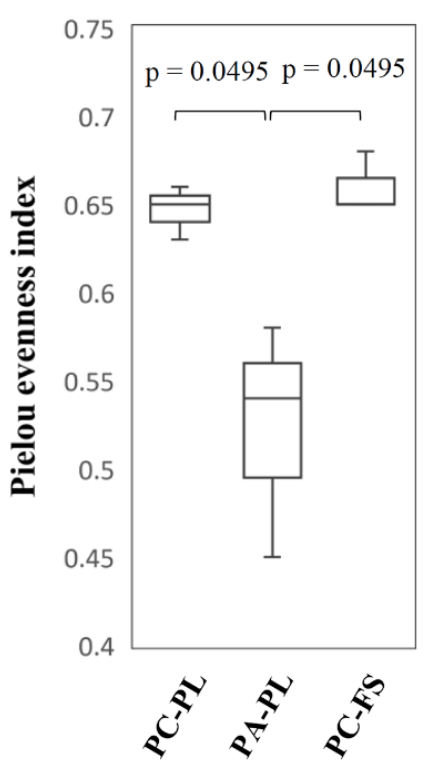

Figure 1. Alpha diversity analysis based on Shannon index (A), observed ASV index (B), and Pielou evenness (C). Samples were rarefied to sampling depth of 17,100 . Kruskal-Wallis test was performed to analyze statistical significance.

Results from the permutational multivariate analysis of variance (pairwise PERMANOVA) showed that there are no statistically significant differences in beta diversity between PC-PL, PA-PL, and PC-FS samples (PC-PL vs. PA-PL $p=0.113$ for Jaccard and $p=0.685$ for Bray-Curtis; PC-PL vs. PC-FS $p=0.106$ for Jaccard and $p=0.093$ for BrayCurtis; PA-PL vs. PC-FS $p=0.105$ for Jaccard and $p=0.103$ for Bray-Curtis). Rarefaction curves showed that all samples reached the saturation phase, and the great majority of microbial diversity was captured (Figure S1). The Principal Coordinate Analysis (PCoA) allowed clear separation of PC-PL, PA-PL, and PC-FS samples, thus pointing to differences in the fungal microbiota composition (Figure 2). 


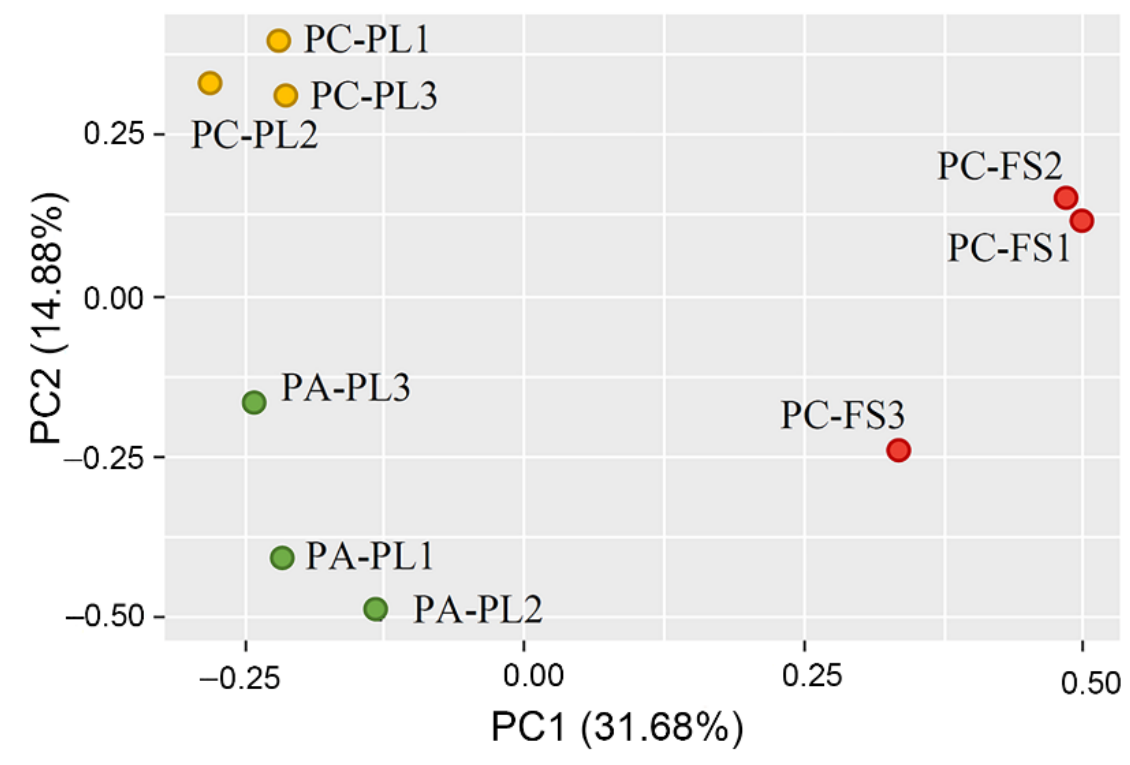

Figure 2. Comparison of fungal microbiota on freshly harvested sour (PC-PL) and sweet cherries (PA-PL), and sour cherries (PC-FS) from a food store by principal coordinate analysis (PCoA). Plots were calculated using Emperor unweighted UniFrac distances. Each dot represents a distinct sample.

\subsection{Fungal Community Profiling}

The metataxonomic analysis of freshly harvested sour and sweet cherries and sour cherries purchased from a local food store revealed a complex fungal microbiota. At the phylum level, the fungal microorganism composition in the freshly harvested sour and sweet cherries showed the highest relative abundance of Ascomycota $(88.70 \%$ for sour cherries and $96.14 \%$ for sweet cherries), which was distributed mainly in four classes: Dothideomycetes, Taphrinomycetes, Leotiomycetes, and Saccharomycetes (Figure 3A, Table S1). The next phylum Basidiomycota (11.02\% for PC-PL and 3.61\% for PA-PL, respectively) was represented by fungi belonging to Tremellomycetes class. On the genus level, the most abundant genera in PC-PL and PA-PL samples were Aureobasidium (25.04\% and $40.63 \%$, respectively), Metschnikowia (12.31 and 20.96\%, respectively), Taphrina (10.23\% and 9.68\%, respectively), Dothiora (9.04\% and $4.46 \%$, respectively), and Cladosporium (3.98\% and $2.85 \%$, respectively) (Figure 3B). On the freshly harvested sour cherries 66 species of fungi were identified and 42 species on sweet cherries (Table S1). Aureobasidium pullulans, Taphrina wiesneri, and Metschnikowia crysoperlae prevailed on both types of freshly harvested berries. The abundance of some yeast species was different on freshly collected sour and sweet cherries, e.g., Hanseniaspora uvarum was more abundant in PA-PL, while more Cladosporium cladosporioides sequences were detected in PC-PL than in PA-PL samples. Certain species were only found on one type of freshly harvested cherries, e.g., Microcyclosporella mali, Ramularia citricola, and Neosetophoma rosae were detected only in PC-PL samples (Table S1).

In store-purchased sour cherry samples, two phylum Ascomycota and Basidiomycota were distributed equally (the relative abundance was $51.37 \%$ and $48.43 \%$, respectively) (Figure 3A). From the first phylum prevailed Aureobasidium (27.35\%), Hanseniaspora (6.96\%), and Cladosporium (6.46\%) genera, and were mainly represented by A. pullulans, H. uvarum, and C. cladosporioides (Figure 3B, Table S1). The Basidiomycota were dominated by yeast from Vishniacozyma (23.32\%), Rhodotorula (7.88\%), and Filobasidium (6.10\%) genera, with the most abundant species being Vishniacozyma heimaeyensis, $V$. victoriae, Rhodotorula graminis, and Filobasidium wieringae (syn. Cryptococcus wieringae) (Figure 3B, Table S1).

A heatmap illustrates the distribution of the most abundant fungal ASVs (Figure 4) revealing the differences between all three groups of berries-freshly harvested sour and sweet cherries, and sour cherries purchased from a local food store. 
A

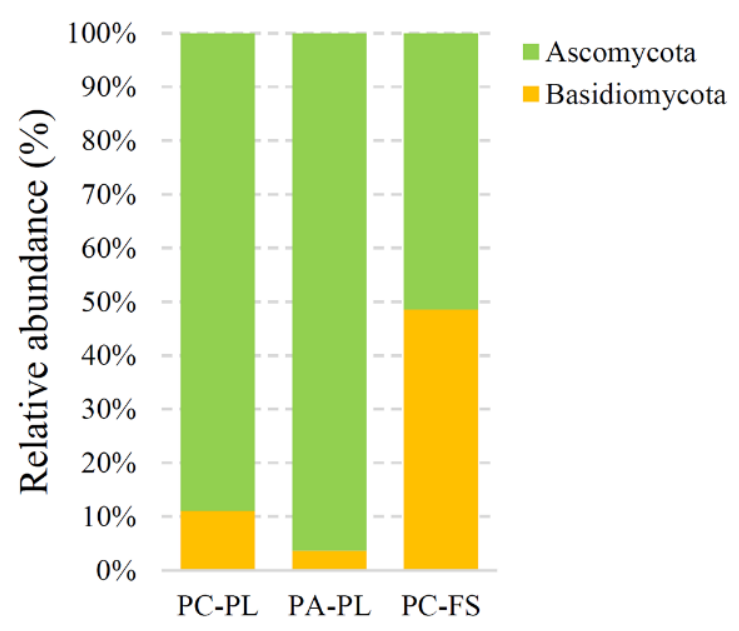

B

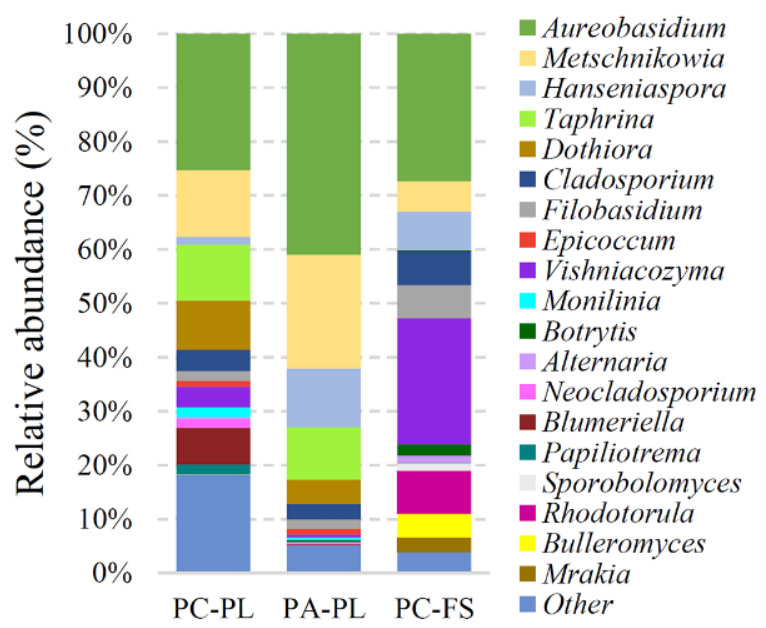

Figure 3. Mycobiota composition on sour (PC-PL) and sweet (PA-PL) cherries sampled from private plantations, and sour cherries (PC-FS) purchased in a food store. Relative abundance of sequences classified at the phylum (A) and genus (B) level. The taxonomic groups comprising less than $1 \%$ of the total composition were assigned to "Other".

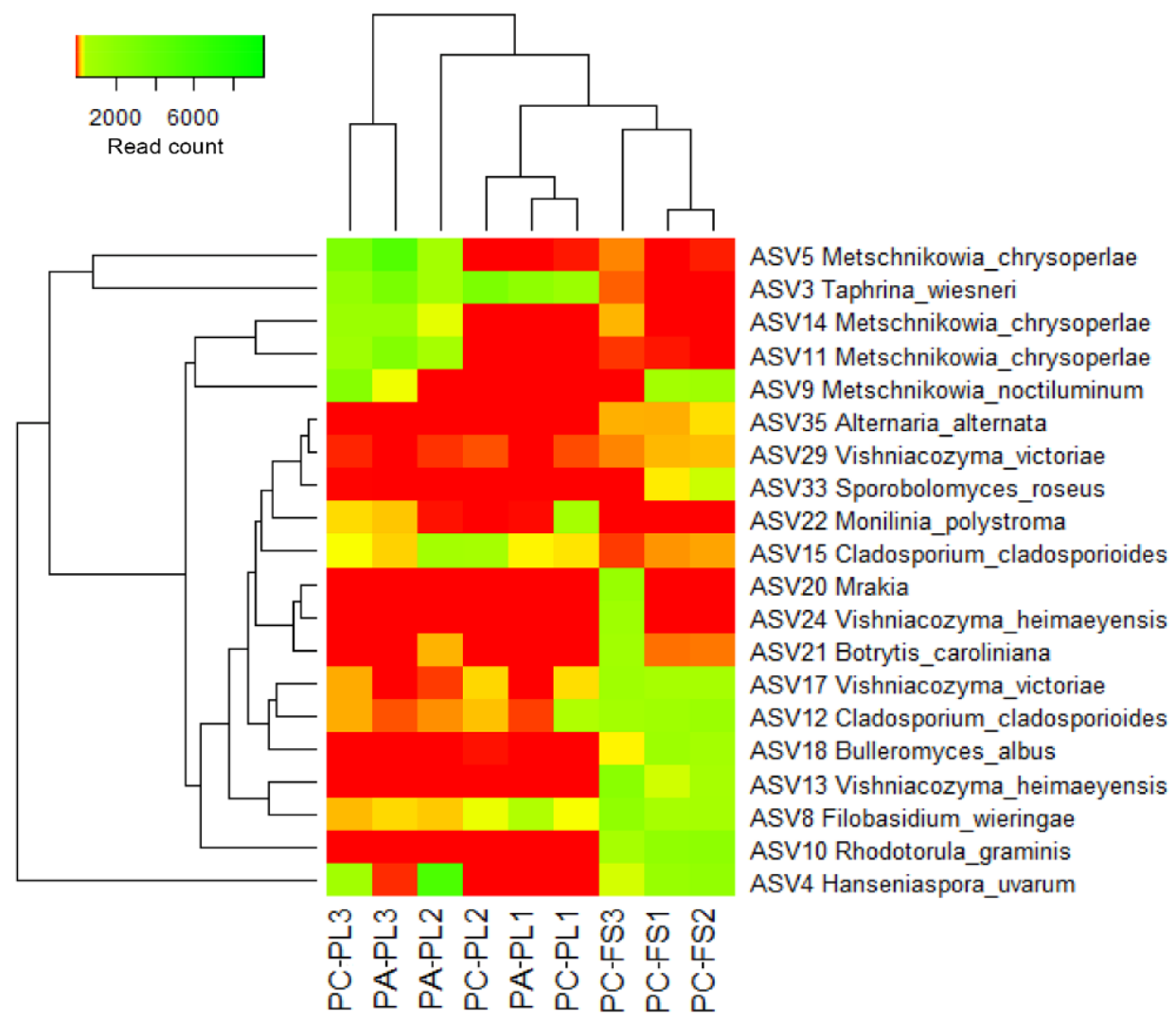

Figure 4. Heatmap of fungal unique amplicon sequence variants (ASVs) abundance on sour and sweet cherries. The color intensity is proportional to the relative abundance of fungi ASVs.

The core microbiomes detected in PC-PL, PA-PL, and PC-FS comprised of ASVs assigned to A. pullulans (Table S1). Based on the distribution pattern of dominating ASVs, PC-PL and PA-PL samples were separated from PC-FS samples, thus indicating on distinct community composition of freshly harvested and store berries. M. crysoperlae (ASVs 5, 11, and 14) and T. wiesneri (ASV 3) were highly associated with freshly harvested P. cerasus and P. avium berries. The abundance of ASVs representing Rhodotorula (ASV 10), Filobasidium 
(ASV 8), Vishniacozyma (ASVs 13 and 17), Cladosporium (ASV 12), and Bulleromyces (ASV 18) genera most likely conditioned clustering of a store sour cherries into a separate group. Some samples of sweet cherries demonstrated high similarity to sour cherries, for example, PC-PL3 and PA-PL3, PC-PL1 and PA-PL1 (Figure 4, Figure S2). This observation may indicate a similar ripening stage of freshly harvested $P$. cerasus and $P$. avium berries in particular samples.

\subsection{Distribution of Cultivable Yeasts on P. avium and P. cerasus}

A culture-based method was used to estimate viable yeast abundance and diversity on sweet and sour cherries. There was no noticeable difference in the overall quantity of yeasts between the samples of sour and sweet cherries collected from private plantations. The viable yeast population on the carposphere of freshly harvested sour cherries was $6.07 \pm 0.31 \log \mathrm{CFU} / \mathrm{g}$ and on sweet cherries was $5.93 \pm 0.25 \log \mathrm{CFU} / \mathrm{g}$. However, sour cherries from a food store did exhibit about 10-fold higher CFU of yeasts per gram of berries (7.17 $\pm 0.12 \log$ CFU $/ g$ ) than freshly sampled berries. Representatives of phenotypically distinct colonies were randomly selected and applied for molecular identification by sequencing of the internal transcribed spacer ITS and/or D1-D2 domains of ribosomal DNA. According to the high similarity of generated sequences to those deposited in the GenBank database, yeast species were identified (Table S2).

In total, 17 yeast species representing 10 genera were detected on freshly picked and food store samples (Table S2). Based on the diversity of isolated yeasts, sample-based variations in both types of berries were observed. A. pullulans yeasts were recovered from all tested samples and were the most dominant in PC-PL1 (84\%), PC-PL2 (69\%), and PAPL1 (92\%) samples (Figure 5, Table S2). Species from Metschnikowia genus (M. pulcherrima, M. fructicola, $M$. sinensis, and $M$. viticola) were detected on most tested berries with a high prevalence on freshly harvested PC-PL3 (64\%) and PA-PL3 (69\%) samples (Figure 5).

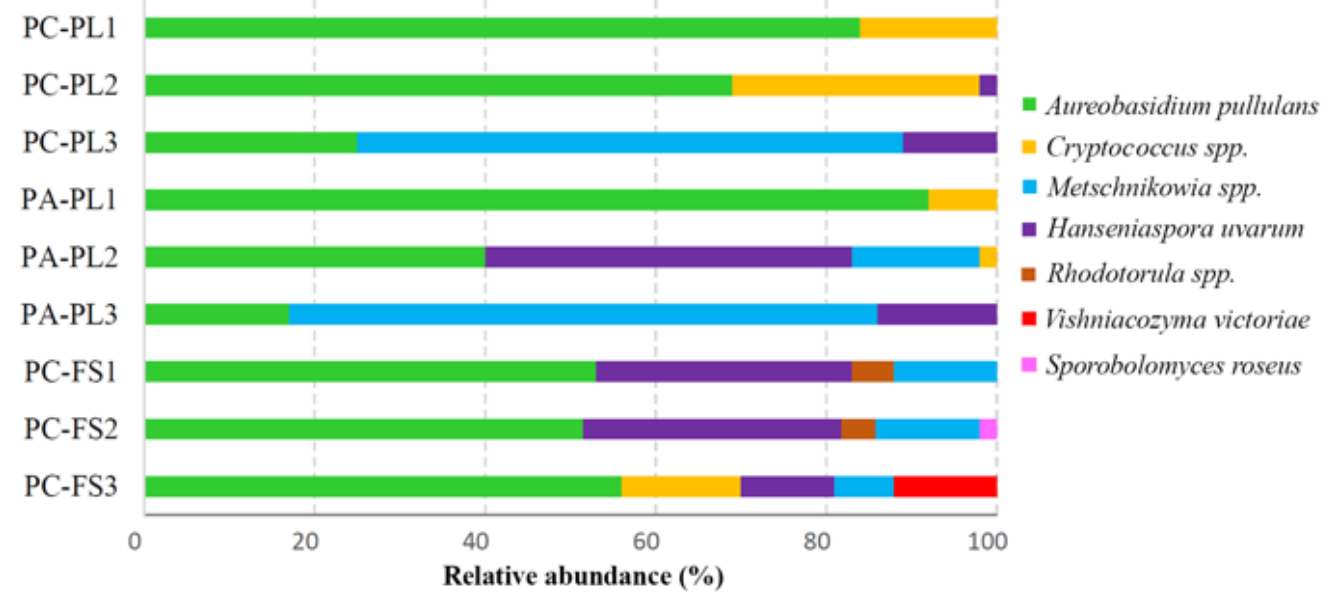

Figure 5. Relative abundance of yeasts isolated from the surface of sour and sweet cherries. Samples of: freshly harvested sour cherries-PC-PL, freshly harvested sweet cherries-PA-PL, food store sour cherries-PC-FS.

Hanseniaspora uvarum yeasts were isolated from all samples except for PC-PL1 and PA-PL1. The highest quantities of H. uvarum were detected on sweet cherries PA-PL2 (43\%) and food store sour cherries in samples PC-FS1 and PC-FS2 (about 30\% in both). The genus Rhodotorula was represented by the species R. graminis, R. glutinis, and R. babjevae, and formed $5-6 \%$ of the total yeast's population on the food store cherries. Species from Cryptococcus genus (C. wieringae and C. pinus) were observed in sour cherry samples PC-PL2 (29\%), PC-PL1 (16\%), PC-FS3 (14\%), and in sweet cherry PA-PL1 (8\%). Some yeast species were not picked up by the direct dilution method and were only detected in low quantities 
after applying culture enrichment. These species include Pichia kluyveri, Saccharomyces paradoxus, Saccharomyces cerevisiae, and Torulaspora delbrueckii (Table S2).

\subsection{Antagonistic Activity of Sour and Sweet Cherries-Associated Yeasts}

Isolated yeasts were subjected to the analysis of killer activity. Out of 50 screened yeast strains (Table S2), 17 exhibited killing activity against S. cerevisiae strain BY4741 (Figure S3). The highest number of yeasts possessing killer features was isolated from PC-PL3 and PA-PL3 samples. They belong to M. pulcherrima, M. fructicola, S. paradoxus, P. kluyveri, and H. uvarum species. No killer yeasts were detected in samples of freshly harvested sweet and sour cherries (PC-PL1 and PA-PL1), and these samples showed low diversity of cultivable yeasts. Four killer yeast strains assigned to M. fructicola, M. sinensis, T. delbrueckii, and H. uvarum were recovered from the food store samples.

The strongest killing ability against $S$. cerevisiae yeasts was demonstrated by $S$. cerevisiae PC-5-8.1 and PA-5-20.1, S. paradoxus PC-5-9.1, and P. kluyveri PC-6-14.1 strains (Figure 6). They formed 3-4 mm lysis zones. The moderate activity against $S$. cerevisiae yeasts was shown by P. kluyveri PA-6-51.1, T. delbrueckii PC-6-18.1, A. pullulans PA-6-56.8, and M. pulcherrima PA-6-26.1 yeasts. The weakest killing properties (inhibition zone size about $0.5 \mathrm{~mm}$ ) showed H. uvarum PC-6-8.1 and PC-6-61.2N, M. fructicola PC-6-17.1, PA-6-34.1N, and PC-612.1, M. pulcherrima PC-1-48.2, M. sinensis PC-6-49.1, S. paradoxus PA-6-10.1, and A. pullulans PC-5-28.1 cultures (Figure 6).

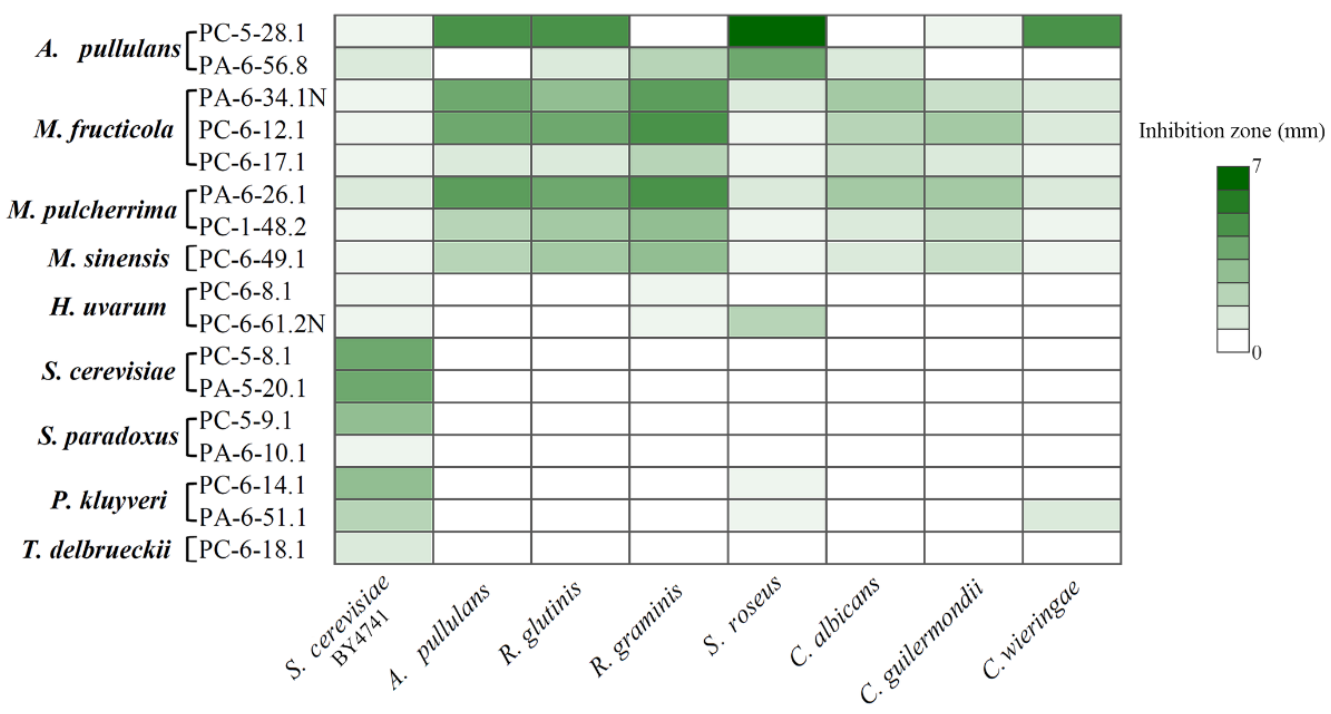

Figure 6. Antagonistic activity of yeasts inhabiting P. cerasus and P. avium surface.

Yeast strains with killing properties were used for the evaluation of antagonistic activity against fungal microorganisms from Aureobasidium, Candida, Cryptococcus, Rhodotorula, and Sporobolomyces genera (Figure 6, Figure S3). Some of these species may be attributed to potential pathogens [30-35]. The halo of inhibition was dependent not only on the species but also on the strain.

Among tested yeasts, M. pulcherrima, M. fructicola, and M. sinensis (in total six strains) exhibited the broadest spectrum of antagonistic activity by inhibiting the growth of all tested yeast species (Figure 6). The highest activity was demonstrated by M. fructicola PA-6-34.1N and PC-6-12.1, as well as M. pulcherrima PA-6-26.1 yeasts against A. pullulans, R. graminis, and R. glutinis species. Potential human pathogens C. albicans and C. guilermondii were also killed effectively by all tested Metschnikowia strains. The weakest antagonistic activity of Metschnikowia spp. strains were determined against $C$. wieringae and S. roseus species. A. pullulans strains PC-5-28.1 and PA-6-56.8 were active against six and five species, respectively. The highest killing activity of $A$. pullulans PC-5-28.1 strain was observed against $S$. roseus, C. wieringae, and non-killer $A$. pullulans strains. This 
yeast-like fungus was able to suppress the growth of potential human pathogens $R$. glutinis and C. guilermondii. The antagonistic activity of another A. pullulans strain PA-6-56.8 was detected against both Rhodotorula species, C. albicans, and S. roseus yeasts. H. uvarum PC6-61.2N and P. kluyveri PA-6-51.1 strains demonstrated killing activity against three yeast species. In addition to antagonistic activity against $S$. cerevisiae and $S$. roseus, the P. kluyveri PA-6-51.1 strain also inhibits the growth of $C$. wieringae, while H. uvarum PC-6-61.2N acts against $R$. graminis. The rest of the tested yeast strains demonstrated antagonistic activity against one or two yeast species.

\section{Discussion}

To date, rather scattered information addresses microbial biodiversity on economically important P. cerasus and P. avium berries. Most of the studies are based on cultivation techniques and are focused on the trees- but not berry-associated microbiota $[18,21,22]$. In the present study, we characterize the composition of fungal communities deposited on sour and sweet cherries, using high-throughput DNA sequencing. To deepen insights into potentially advantageous or dangerous microorganisms inhabiting tested berries, NGS approach was supplemented with cultivation-based experiments. Our study provides valuable data on the differences in epiphytic mycobiota structure of environmental, freshly collected berries and those purchased in a food store.

On freshly harvested sour and sweet cherries, members of Ascomycota were found with higher frequency than those of Basidiomycota. Obtained results are in concord with the previous studies accomplished with fresh-cut fruits such as apple, red and black currants, sea buckhorn, etc. $[14,16,17,23,36]$. Ascomycetous fungi distributed on the tested berries were mainly represented by Aureobasidium, Cladosporium, Metschnikowia, Hanseniaspora, and Taphrina genera. It was previously demonstrated that intact berries were dominated by Aureobasidium, Taphrina, and Cladosporium fungi [14,37]. During the ripening process, fermentative ascomycetous microorganisms, such as Metschnikowia, Candida, and Hanseniaspora increased in frequency [14,37]. In our study, the heterogeneous microbial composition of the individual sweet and sour cherry samples was observed starting from the class level and this could be due to the uneven ripening stage of harvested berries. Increased distribution of Metschnikowia (in PC-PL3, PA-PL2, and PA-PL3 samples) and Hanseniaspora (in PA-PL2) genera yeasts suggests a higher ripening stage of berries in these samples, compared to other samples of freshly picked berries. At the same time, an increased level of Aureobasidium in PC-PL1 and PA-PL1 samples may be an indication of incomplete ripeness.

Among the most abundant genera inhabiting the surface of freshly picked sour and sweet cherries, fungi with previously reported beneficial biocontrol features were observed [13]. Epiphytic yeasts represent the greatest share of the fungal fruit-associated microbial community. They are successfully adapted to various environmental conditions and seem to be promising biological control candidates [38]. A. pullulans was the most abundant yeast-like fungus identified on the examined sour and sweet cherries. Numerous studies have revealed that some $A$. pullulans isolates due to the production of volatile organic compounds, enzymes, or toxins demonstrated antagonistic activity against various fungal and bacterial pathogens, such as Botrytis, Bacillus, Colletotrichum, Geotrichum, Penicillium [14,39-41]. In the present study, two strains of $A$. pullulans with a broad spectrum of antagonistic activity against potential phytopathogens or fungal microorganisms potentially harmful for humans were isolated. Metschnikowia spp. are sugar-rich fruit surface inhabiting species, found on apples, grapes, pears, raspberries, currants, strawberries, and plums $[38,42,43]$. These yeasts could be transported to new niches by insects and serve them as a food source $[43,44]$. In our study, Metschnikowia spp. yeasts were identified on the tested berries by NGS technique, and numerous species (such as M. pulcherrima, M. fructicola, M. sinensis, M. viticola) were isolated using plate dilution assay. It is known that some strains of $M$. pulcherrima, M. fructicola, and $M$. sinensis have a strong biocontrol activity against various microorganisms, due to the synthesis of volatile organic compounds, iron 
immobilizing pigment pulcherrimin, or killer toxins [38,45-50]. These yeasts are of the greatest interest as potential inhibitors of pathogenic microorganisms [38]. About half of Metschnikowia spp. strains isolated in our study also exhibited pronounced antagonistic activity against all tested fungal microorganisms, thus could be attractive for disease management. Hanseniaspora spp. have been frequently found on mature fruits such as apple, grape, plum, and sea buckthorn $[14,43,51]$. Some Hanseniaspora genus species, especially H. uvarum, display industrially significant antagonistic properties against fungi pathogenic to humans (Trichophyton mentagrophytes and T. rubrum) and plants (Botrytis cinerea, Colletotrichum capsica, Fusarium solani, Penicillium spp. and Sclerotinia sclerotiorum) [52-54]. Antimicrobial activity against pathogenic bacteria Staphylococcus aureus, Escherichia coli, Klebsiella pneumonia, and Pseudomonas aeruginosa was attributed to H. uvarum encoded killer toxin [54]. In our study, two isolated H. uvarum strains exhibited killing activity against $R$. graminis and S. cerevisiae yeasts, demonstrating their biocontrol potential. The members of Saccharomycetes, such as P. kluyveri, S. cerevisiae, S. paradoxus, and T. delbrueckii, were detected on sweet and sour cherries at a low level. Our observation agrees with previous studies performed on apple, plum, grape, and pear fruits $[43,55,56]$. Even at low quantities such yeasts could act as biocontrol agents and regulate the structure of plant microbiota [17].

The number of fungi from Basidiomycota phylum was higher in food store sour cherries and reached a similar level as Ascomycota representatives, and may be related to both fruit and postharvest handling-dependent occurrence. It is well established that various treatments and conditions can affect the composition of the microbial community [57]. Postharvest processing of fruits, packaging, and distribution may condition microbial contamination harmful for consumer health [18]. The abundance of microorganisms can be decreased or avoided by good harvesting and handling practice, cool storage of fruits, and usage of chemicals or fungicides [18].

We observed a high frequency of potentially pathogenic fungi from the genera of Rhodotorula, Vishniacozyma, Filobasidium (syn. Cryptococcus), and Sporobolomyces on the purchased sour cherries. We demonstrated that isolated strains from the mentioned above species did not possess any antimicrobial activity against tested microorganisms. Rhodotorula spp. are ubiquitous yeasts that can be recovered from many environmental sources, including fruits. Some Rhodotorula species, such as R. graminis, R. mucilaginosa, and $R$. babjevae award growth benefits to plants, enrich their biochemical properties [58-60]. Rhodotorula yeasts exhibit strong biocontrol activity against fungal and bacterial pathogens, especially towards B. cinerea and P. expansum [59]. On the other hand, some species such as R. mucilaginosa, R. glutinis, and R. minuta have emerged as opportunistic pathogens that can infect humans with the weakened immune system and cause a variety of systemic infections [35]. Some Sporobolomyces and Vishniacozyma species showed biocontrol advantages by reducing the growth of blue and gray mold [61,62]. On the other hand, S. roseus yeasts are documented as one of the yeasts involved in the candied fruit and nougat spoilage, thus rendering inconvenience for the food industry [30]. The danger is even more sound considering that these species may cause infection in immunocompromised patients [32]. Cryptococcus spp. are typical members of the yeast community on fruits at an early stage of maturation $[43,63]$. These ubiquitous fungi enclose species producing biocontrol agents against many pathogens [13,64], while particular species can be dangerous for humans [31].

Our findings suggest that fungal communities on the surface of sour cherries purchased from a food store inhabit more controversial yeast genera than the freshly picked berries in terms of described yeasts that have attractive or undesirable properties for food safety and human health. We have also observed stronger antagonistic properties against tested yeast species of strains isolated from freshly picked cherries than in the samples of store berries. The examination of fungal communities of P. cerasus L. and P. avium L. fruits enabled the isolation of various yeast strains with a high biocontrol potential and further research is required to better reveal the value of these microscopic fungi. 


\section{Conclusions}

This is the first manuscript characterizing fungal communities on sweet and sour cherry fruits by applying NGS approach and cultivation-based techniques. Our data show the plant-conditioned prevalence of microorganisms and demonstrate the influence of postharvest handling, such as food store management, on the structure of mycobiota. Investigation of microbial ASVs diversity showed a clear separation of fungal assemblages on freshly harvested and food store cherries. Among the fungi inhabiting tested berries, potentially beneficial or pathogenic fungi were documented. Numerous cultivable yeasts were isolated from the surface of tested berries and evaluated for their antagonistic activity. The prominent antagonistic activity of cultivable yeasts isolated from freshly harvested cherries against potential pathogens highlights the attractiveness of these strains for the management of disease control.

Supplementary Materials: The following are available online at https: / www.mdpi.com/article/ 10.3390/microorganisms9071423/s1, Figure S1: Rarefaction curves at a genetic distance of 3\% for each sample; Figure S2: Fungal taxonomy relative abundance at phylum (A) and genus (B) level for samples of freshly harvested sweet and sour cherries as well as sour cherries from the food store; Figure S3: Yeast antagonistic activity assay; Table S1: Fungal communities associated with freshly harvested and food store-purchased Prunus cerasus and Prunus avium berries; Table S2: Yeast isolates detected in this study.

Author Contributions: Conceptualization, E.S.; methodology, Ž.S.-Ž., B.R., R.S., E.S.; investigation, R.S., Ž.S.-Ž., B.R., R.L.-S.; software and bioinformatics, J.L.; formal analysis, J.L., R.S., Ž.S.-Ž., B.R., E.S.; resources, E.S., R.M.; data interpretation, E.S.; funding acquisition, R.M.; writing-original draft, E.S., J.L., B.R.; writing-review \& editing, E.S., B.R., J.L. All authors have read and agreed to the published version of the manuscript.

Funding: This research has received funding from European Social Fund (project number 09.3.3LMT-K-712-01-0099) under grant agreement with the Research Council of Lithuania (LMTLT).

Institutional Review Board Statement: Not applicable.

Informed Consent Statement: Not applicable.

Data Availability Statement: Not applicable.

Conflicts of Interest: The authors declare no conflict of interest. The funders had no role in the design of the study; in the collection, analyses, or interpretation of data; in the writing of the manuscript; or in the decision to publish the results.

\section{References}

1. Daenen, L.; Sterckx, F.; Delvaux, F.R.; Verachtert, H.; Derdelinckx, G. Evaluation of the Glycoside Hydrolase Activity of a Brettanomyces Strain on Glycosides from Sour Cherry (Prunus cerasus L.) Used in the Production of Special Fruit Beers. FEMS Yeast Res. 2008, 8, 1103-1114. [CrossRef] [PubMed]

2. De Rogatis, A.; Ferrazzini, D.; Ducci, F.; Guerri, S.; Carnevale, S.; Belletti, P. Genetic Variation in Italian Wild Cherry (Prunus Avium L.) as Characterised by NSSR Markers. Forestry 2013, 2013, 1-10. [CrossRef]

3. Kelley, D.S.; Adkins, Y.; Laugero, K.D. A Review of the Health Benefits of Cherries. Nutrients 2018, 10, 368. [CrossRef] [PubMed]

4. Morales-Corts, M.R.; Rodrigues, L.; Ortiz, J.; Sánchez, R. Characterization of Sour (Prunus cerasus L.) and Sweet Cherry (Prunus Avium L.) Varieties with Five Isozyme Systems. Rev. Bras. Frutic. 2008, 30. [CrossRef]

5. Martinelli, I.; Micioni Di Bonaventura, M.V.; Moruzzi, M.; Amantini, C.; Maggi, F.; Gabrielli, M.G.; Fruganti, A.; Marchegiani, A.; Dini, F.; Marini, C.; et al. Effects of Prunus cerasus L. Seeds and Juice on Liver Steatosis in an Animal Modelof Diet-Induced Obesity. Nutrients 2020, 12, 1308. [CrossRef]

6. Commisso, M.; Bianconi, M.; Di Carlo, F.; Poletti, S.; Bulgarini, A.; Munari, F.; Negri, S.; Stocchero, M.; Ceoldo, S.; Avesani, L.; et al. Multi-Approach Metabolomics Analysis and Artificial Simplified Phytocomplexes Reveal Cultivar-Dependent Synergy between Polyphenols and Ascorbic Acid in Fruits of the Sweet Cherry (Prunus avium L.). PLoS ONE 2017, 12, e0180889. [CrossRef] [PubMed]

7. Zhang, H.; Li, Q.; Qiao, G.; Qiu, Z.; Wen, Z.; Wen, X. Optimizing the Supercritical Carbon Dioxide Extraction of Sweet Cherry (Prunus avium L.) Leaves and UPLC-MS/MS Analysis. Anal. Methods 2020, 12, 3004-3013. [CrossRef]

8. Fazzari, M.; Fukumoto, L.; Mazza, G.; Livrea, M.A.; Tesoriere, L.; Di Marco, L. In Vitro Bioavailability of Phenolic Compounds from Five Cultivars of Frozen SweetCherries (Prunus avium L.). J. Agric. Food Chem. 2008, 56, 3561-3568. [CrossRef] 
9. Pinto, C.; Pinho, D.; Sousa, S.; Pinheiro, M.; Egas, C.; Gomes, A.C. Unravelling the Diversity of Grapevine Microbiome. PLoS ONE 2014, 9, e85622. [CrossRef]

10. Pinto, C.; Pinho, D.; Cardoso, R.; Custódio, V.; Fernandes, J.; Sousa, S.; Pinheiro, M.; Egas, C.; Gomes, A.C. Wine Fermentation Microbiome: A Landscape from Different Portuguese WineAppellations. Front. Microbiol. 2015, 6, 905. [CrossRef]

11. Martins, G.; Miot-Sertier, C.; Lauga, B.; Claisse, O.; Lonvaud-Funel, A.; Soulas, G.; Masneuf-Pomarède, I. Grape Berry Bacterial Microbiota: Impact of the Ripening Process and the FarmingSystem. Int. J. Food Microbiol. 2012, 158, 93-100. [CrossRef]

12. Janisiewicz, W.J.; Jurick, W.M., 2nd; Peter, K.A.; Kurtzman, C.P.; Buyer, J.S. Yeasts Associated with Plums and Their Potential for Controlling Brown Rot afterHarvest. Yeast 2014, 31, 207-218. [CrossRef] [PubMed]

13. Freimoser, F.M.; Rueda-Mejia, M.P.; Tilocca, B.; Migheli, Q. Biocontrol Yeasts: Mechanisms and Applications. World J. Microbiol. Biotechnol. 2019, 35, 154. [CrossRef] [PubMed]

14. Lukša, J.; Vepštaitè-Monstavičè, I.; Apšegaitè, V.; Blažytė-Čereškienè, L.; Stanevičienè, R.; Strazdaitė-Žielienė, Ž.; Ravoitytè, B.; Aleknavičius, D.; Būda, V.; Mozūraitis, R.; et al. Fungal Microbiota of Sea Buckthorn Berries at Two Ripening Stages and VolatileProfiling of Potential Biocontrol Yeasts. Microorganisms 2020, 8, 456. [CrossRef]

15. Coutinho, T.A.; Venter, S.N. Pantoea Ananatis: An Unconventional Plant Pathogen. Mol. Plant Pathol. 2009, 10, 325-335. [CrossRef]

16. Lukša, J.; Vepštaitè-Monstavičè, I.; Yurchenko, V.; Serva, S.; Servienè, E. High Content Analysis of Sea Buckthorn, Black Chokeberry, Red and White CurrantsMicrobiota-A Pilot Study. Food Res. Int. 2018, 111, 597-606. [CrossRef]

17. Abdelfattah, A.; Wisniewski, M.; Li Destri Nicosia, M.G.; Cacciola, S.O.; Schena, L. Metagenomic Analysis of Fungal Diversity on Strawberry Plants and the Effect of Management Practices on the Fungal Community Structure of Aerial Organs. PLoS ONE 2016, 11, e0160470. [CrossRef]

18. Pintér, S.; Bata-Vidács, I.; Beczner, J. Epiphytic Microbiota of Sour Cherry (Prunus cerasus L.) in Integrated and Organic Growing. Acta Aliment. 2013, 42, 618-630. [CrossRef]

19. Liang, S.; Liu, H.; Wu, S.; Xu, S.; Jin, D.; Faiola, F.; Zhuang, X.; Zhuang, G.; Qu, D.; Fan, H.; et al. Genetic Diversity of Diazotrophs and Total Bacteria in the Phyllosphere of Pyrus serotina, Prunus armeniaca, Prunus avium, and Vitis vinifera. Can. J. Microbiol. 2019, 65, 642-652. [CrossRef] [PubMed]

20. Toledo Del Árbol, J.; Pérez Pulido, R.; La Storia, A.; Grande Burgos, M.J.; Lucas, R.; Ercolini, D.; Gálvez, A. Microbial Diversity in Pitted Sweet Cherries (Prunus Avium L.) as Affected byHigh-Hydrostatic Pressure Treatment. Food Res. Int. 2016, 89, 790-796. [CrossRef]

21. Abdollahi Aghdam, S.; Fotouhifar, K.-B. New Reports of Endophytic Fungi Associated with Cherry (Prunus avium) and Sour Cherry (Prunus cerasus) Trees in Iran. Mycol. Iran. 2016, 3, 75-85. [CrossRef]

22. Bien, S.; Damm, U. Prunus Trees in Germany-A Hideout of Unknown Fungi? Mycol. Prog. 2020, 19, 667-690. [CrossRef]

23. Vepštaitè-Monstavičè, I.; Lukša, J.; Stanevičienè, R.; Strazdaitė-Žielienė, Ž.; Yurchenko, V.; Serva, S.; Servienè, E. Distribution of Apple and Blackcurrant Microbiota in Lithuania and the CzechRepublic. Microbiol. Res. 2018, 206, 1-8. [CrossRef]

24. Bolyen, E.; Rideout, J.R.; Dillon, M.R.; Bokulich, N.A.; Abnet, C.C.; Al-Ghalith, G.A.; Alexander, H.; Alm, E.J.; Arumugam, M.; Asnicar, F.; et al. Reproducible, Interactive, Scalable and Extensible Microbiome Data Science UsingQIIME 2. Nat. Biotechnol. 2019, 37, 852-857. [CrossRef]

25. Martin, M. Cutadapt Removes Adapter Sequences from High-Throughput Sequencing Reads. EMBnet. J. 2011, 17. [CrossRef]

26. Callahan, B.J.; McMurdie, P.J.; Rosen, M.J.; Han, A.W.; Johnson, A.J.A.; Holmes, S.P. DADA2: High-Resolution Sample Inference from Illumina Amplicon Data. Nat. Methods 2016, 13, 581-583. [CrossRef] [PubMed]

27. Bokulich, N.A.; Kaehler, B.D.; Rideout, J.R.; Dillon, M.; Bolyen, E.; Knight, R.; Huttley, G.A.; Gregory Caporaso, J. Optimizing Taxonomic Classification of Marker-Gene Amplicon Sequences with QIIME 2'sQ2-Feature-Classifier Plugin. Microbiome 2018, 6, 90. [CrossRef] [PubMed]

28. Horikoshi, M.; Tang, Y. Ggfortify: Data Visualization Tools for Statistical Analysis Results. 2018. Available online: https: / /CRAN.R-project.org / package=ggfortify (accessed on 22 February 2021).

29. Warnes, G.; Bolker, B.; Bonebakker, L.; Gentleman, R.; Huber, W.; Liaw, A.; Lumley, T.; Mächler, M.; Magnusson, A.; Möller, S. Gplots: Various R Programming Tools for Plotting Data. 2005. Available online: https: / CRAN.R-project.org/package=gplots (accessed on 24 February 2021).

30. Martorell, P.; Fernández-Espinar, M.T.; Querol, A. Molecular Monitoring of Spoilage Yeasts during the Production of Candied FruitNougats to Determine Food Contamination Sources. Int. J. Food Microbiol. 2005, 101, 293-302. [CrossRef] [PubMed]

31. Bernal-Martinez, L.; Gomez-Lopez, A.; Castelli, M.V.; Mesa-Arango, A.C.; Zaragoza, O.; Rodriguez-Tudela, J.L.; Cuenca-Estrella, M. Susceptibility Profile of Clinical Isolates of Non-Cryptococcus neoformans/Non-Cryptococcus gattii Cryptococcus Species and Literature Review. Med. Mycol. 2010, 48, 90-96. [CrossRef] [PubMed]

32. McNicholas, S.; McDermott, H.; Power, L.; Johnson, E.M.; Moroney, J.; Humphreys, H.; Smyth, E.G. Sporobolomyces roseus in the Cerebrospinal Fluid of an Immunocompetent Patient-toTreat or Not to Treat? J. Med. Microbiol. 2012, 61, 295-296. [CrossRef]

33. Liu, D.; Ma, L.; Shi, Y.; Wang, A.; Liu, C. Molecular Diagnosis and Source Tracing of an Infection of Aureobasidium pullulans. J. Infect. Dev. Ctries. 2019, 13, 1174-1179. [CrossRef] [PubMed]

34. Talapko, J.; Juzbašić, M.; Matijević, T.; Pustijanac, E.; Bekić, S.; Kotris, I.; Škrlec, I. Candida Albicans-The Virulence Factors and Clinical Manifestations of Infection. J. Fungi 2021, 7, 79. [CrossRef] [PubMed] 
35. Wirth, F.; Goldani, L.Z. Epidemiology of Rhodotorula: An Emerging Pathogen. Interdiscip. Perspect. Infect. Dis. $2012,465717$. [CrossRef]

36. Abdelfattah, A.; Freilich, S.; Bartuv, R.; Zhimo, V.Y.; Kumar, A.; Biasi, A.; Salim, S.; Feygenberg, O.; Burchard, E.; Dardick, C.; et al. Global Analysis of the Apple Fruit Microbiome: Are All Apples the Same? Environ. Microbiol. 2021. [CrossRef]

37. Barata, A.; Malfeito-Ferreira, M.; Loureiro, V. Changes in Sour Rotten Grape Berry Microbiota during Ripening and Wine Fermentation. Int. J. Food Microbiol. 2012, 154, 152-161. [CrossRef]

38. Pawlikowska, E.; James, S.A.; Breierova, E.; Antolak, H.; Kregiel, D. Biocontrol Capability of Local Metschnikowia sp. Isolates. Antonie Van Leeuwenhoek 2019, 112, 1425-1445. [CrossRef]

39. Moura, V.S.; Pollettini, F.L.; Ferraz, L.P.; Mazzi, M.V.; Kupper, K.C. Purification of a Killer Toxin from Aureobasidium pullulans for the Biocontrol of Phytopathogens. J. Basic Microbiol. 2021, 61, 77-87. [CrossRef]

40. Tilocca, B.; Cao, A.; Migheli, Q. Scent of a Killer: Microbial Volatilome and Its Role in the Biological Control of Plant Pathogens. Front. Microbiol. 2020, 11, 41. [CrossRef]

41. Parafati, L.; Vitale, A.; Restuccia, C.; Cirvilleri, G. Biocontrol Ability and Action Mechanism of Food-Isolated Yeast Strains against Botrytis cinerea Causing Post-Harvest Bunch Rot of Table Grape. Food Microbiol. 2015, 47, 85-92. [CrossRef]

42. Kurtzman, C.P.; Droby, S. Metschnikowia fructicola, a New Ascosporic Yeast with Potential for Biocontrol of Postharvest Fruit Rots. Syst. Appl. Microbiol. 2001, 24, 395-399. [CrossRef] [PubMed]

43. Vadkertiová, R.; Molnárová, J.; Vránová, D.; Sláviková, E. Yeasts and Yeast-like Organisms Associated with Fruits and Blossoms of Different Fruit Trees. Can. J. Microbiol. 2012, 58, 1344-1352. [CrossRef]

44. Lachance, M.A.; Starmer, W.T.; Rosa, C.A.; Bowles, J.M.; Barker, J.S.; Janzen, D.H. Biogeography of the Yeasts of Ephemeral Flowers and Their Insects. FEMS Yeast Res. 2001, 1, 1-8. [CrossRef]

45. Büyüksırıt Bedir, T.; Kuleaşan, H. A Natural Approach, the Use of Killer Toxin Produced by Metschnikowia pulcherrima in Fresh Ground Beef Patties for Shelf Life Extention. Int. J. Food Microbiol. 2021, 345, 109154. [CrossRef]

46. Janisiewicz, W.J.; Tworkoski, T.J.; Kurtzman, C.P. Biocontrol Potential of Metchnikowia Pulcherrima Strains Against Blue Mold of Apple. Phytopathology 2001, 91, 1098-1108. [CrossRef] [PubMed]

47. Piombo, E.; Sela, N.; Wisniewski, M.; Hoffmann, M.; Gullino, M.L.; Allard, M.W.; Levin, E.; Spadaro, D.; Droby, S. Genome Sequence, Assembly and Characterization of Two Metschnikowia fructicola Strains Used as Biocontrol Agents of Postharvest Diseases. Front. Microbiol. 2018, 9, 593. [CrossRef]

48. Sipiczki, M. Metschnikowia Strains Isolated from Botrytized Grapes Antagonize Fungal and Bacterial Growth by Iron Depletion. Appl. Environ. Microbiol. 2006, 72, 6716-6724. [CrossRef] [PubMed]

49. Tan, C.; Wang, L.; Xue, Y.; Lin, S.; Yu, G.; Yang, S. Purification and Molecular Characterization of a Metschnikowia saccharicola Killer Toxin Lethal to a Crab Pathogenic Yeast. FEMS Microbiol. Lett. 2018, 365. [CrossRef]

50. Vicente, J.; Ruiz, J.; Belda, I.; Benito-Vázquez, I.; Marquina, D.; Calderón, F.; Santos, A.; Benito, S. The Genus Metschnikowia in Enology. Microorganisms 2020, 8, 1038. [CrossRef]

51. Graça, A.; Santo, D.; Esteves, E.; Nunes, C.; Abadias, M.; Quintas, C. Evaluation of Microbial Quality and Yeast Diversity in Fresh-Cut Apple. Food Microbiol. 2015, 51, 179-185. [CrossRef]

52. Albertin, W.; Setati, M.E.; Miot-Sertier, C.; Mostert, T.T.; Colonna-Ceccaldi, B.; Coulon, J.; Girard, P.; Moine, V.; Pillet, M.; Salin, F.; et al. Hanseniaspora uvarum from Winemaking Environments Show Spatial and Temporal Genetic Clustering. Front. Microbiol. 2015, 6, 1569. [CrossRef]

53. Cai, Z.; Yang, R.; Xiao, H.; Qin, X.; Si, L. Effect of Preharvest Application of Hanseniaspora uvarum on Postharvest Diseases in Strawberries. Postharvest Biol. Technol. 2015, 100, 52-58. [CrossRef]

54. Al-qaysi, S. Killer Activity of Hanseniaspora uvarum Isolated from Dates Vinegar: Partially Purification and Characterization of Killer Toxin. Baghdad Sci. J. 2019, 16, 140-150. [CrossRef]

55. Raspor, P.; Milek, D.M.; Polanc, J.; Mozina, S.S.; Cadez, N. Yeasts Isolated from Three Varieties of Grapes Cultivated in Different Locations of the Dolenjska Vine-Growing Region, Slovenia. Int. J. Food Microbiol. 2006, 109, 97-102. [CrossRef]

56. Pelliccia, C.; Antonielli, L.; Corte, L.; Bagnetti, A.; Fatichenti, F.; Cardinali, G. Preliminary Prospection of the Yeast Biodiversity on Apple and Pear Surfaces from Northern Italy Orchards. Ann. Microbiol. 2011, 61, 965-972. [CrossRef]

57. Diskin, S.; Feygenberg, O.; Feygenberg, D.; Droby, S.; Prusky, D.; Alkan, N. Microbiome Alterations Are Correlated with Occurrence of Postharvest Stem-End Rot in Mango Fruit. Phytobiomes 2017, 1. [CrossRef]

58. Firrincieli, A.; Otillar, R.; Salamov, A.; Schmutz, J.; Khan, Z.; Redman, R.S.; Fleck, N.D.; Lindquist, E.; Grigoriev, I.V.; Doty, S.L. Genome Sequence of the Plant Growth Promoting Endophytic Yeast Rhodotorula graminis WP1. Front. Microbiol. $2015,6,978$. [CrossRef]

59. Sen, S.; Borah, S.N.; Bora, A.; Deka, S. Production, Characterization, and Antifungal Activity of a Biosurfactant Produced by Rhodotorula babjevae YS3. Microb. Cell Fact. 2017, 16, 95. [CrossRef] [PubMed]

60. Sen, D.; Paul, K.; Saha, C.; Mukherjee, G.; Nag, M.; Ghosh, S.; Das, A.; Seal, A.; Tripathy, S. A Unique Life-Strategy of an Endophytic Yeast Rhodotorula Mucilaginosa JGTA-S1-a Comparative Genomics Viewpoint. DNA Res. 2019, 26, 131-146. [CrossRef] [PubMed]

61. Janisiewicz, W. Control of Storage Decay of Apples with Sporobolomyces roseus. Plant Dis. 1994, 78, 466. [CrossRef]

62. Gramisci, B.R.; Lutz, M.C.; Lopes, C.A.; Sangorrín, M.P. Enhancing the Efficacy of Yeast Biocontrol Agents against Postharvest Pathogens through Nutrient Profiling and the Use of Other Additives. Biol. Control 2018, 121, 151-158. [CrossRef] 
63. Janisiewicz, W.J.; Kurtzman, C.P.; Buyer, J.S. Yeasts Associated with Nectarines and Their Potential for Biological Control of Brown Rot. Yeast 2010, 27, 389-398. [CrossRef] [PubMed]

64. Hashem, M.; Alamri, S.A.; Hesham, A.E.-L.; Al-Qahtani, F.M.H.; Kilany, M. Biocontrol of Apple Blue Mould by New Yeast Strains: Cryptococcus albidus KKUY0017 and Wickerhamomyces anomalus KKUY0051 and Their Mode of Action. Biocontrol Sci. Technol. 2014, 24, 1137-1152. [CrossRef] 